\title{
WOMEN'S STUDIES CURRICULUM DEVELOPMENT: A VIEW FROM THE UNITED STATES
}

\author{
MARY I. EDWARDS \\ Women's Studies Program, The University of Michigan, Ann Arbor, MI 48109, U.S.A.
}

(Received and accepted August 1978)

Women's Studies in the United States has long been concerned with curriculum development. In 1970 descriptions of Women's Studies courses began to be published in the Female Studies Series. ${ }^{1}$ Since then many feminist journals primarily devoted to scholarship have published bibliographies for teachers, descriptions of the curriculum in Women's Studies programs, and articles assessing the impact of Women's Studies in the classroom. ${ }^{2}$ Researchoriented conferences in the traditional disciplines often include workshops on teaching Women's Studies, and regional as well as national conferences on Women's Studies still focus in part on curriculum and pedagogy.

For practical and ideological reasons Women's Studies has emphasized a collectively designed curriculum. Early Women's Studies teachers found common ground in their disciplines' failure adequately to treat the subject of women, and the resulting scarcity of good classroom materials forced them to pool resources. The spirit of co-operation fostered by these conditions found an ideological framework in contemporary feminism's ideal of collective work. Distrustful of the single-minded competition which had alienated male colleagues from each other, Women's Studies teachers wanted to develop more co-operative structures in academia; collective decision-making, team-teaching, and collective curriculum-planning were part of that effort.

In designing the curriculum the first teachers of Women's Studies were also defining the field. While the scholarship which would define an interdisciplinary field of study was slowly emerging, Women's Studies teachers were faced with a vexed problem in definition: what is Women's Studies? What does it include? The subject was criticized for being diffuse, too 'personal', not 'scholarly', partly because it took seriously the study of women's experience but also because of the high visibility of many related activities, what we might call 'applied Women's Studies'. When workshops on assertiveness training, continuing education programs for returning women students, in-service training on sexism for public school teachers, all call themselves 'Women's Studies', how does one define an academic subject? Faculty in the research universities and liberal arts colleges needed to distinguish Women's Studies from these advocacy or training programs, while Women's Studies teachers in less traditional institutions needed to know how to incorporate the growing body of feminist scholarship into their more broadly conceived Women's Studies courses.

When teachers of Women's Studies at institutions in Southern Michigan met together, they often shared these concerns. Faculty in the community colleges complained that they were expected to teach Women's Studies because they were female or politically active 
feminists; they were willing but unprepared to do so. Others reported that their geographical isolation in remote, rural settings removed them from research networks where the as yet unpublished scholarly studies were being circulated. Teachers at all institutions felt constrained by the narrowness of their own disciplinary training, and wanted to have a solid grasp on the central debates on women in the social sciences and humanities. Everyone spoke of the need for accessible and useful curricular materials.

In the Winter of 1976 The University of Michigan Women's Studies Program decided to address these regional needs by seeking funds from the National Endowment for the Humanities. We envisioned an eighteen-month project, at the center of which would be a Research on Women Seminar bringing together Women's Studies scholars and teachers in Southern Michigan. The seminar's purposes were to examine the new scholarship on women in order to determine how it could best be integrated into Women's Studies courses, and to discuss the particular pedadogical problems that Women's Studies teachers face. The second phase of the project was to develop new curricular materials which would incorporate and evaluate the well-known scholarship on women as well as make available current research. We hoped to design courses in four broadly defined interdisciplinary subject areas where the resources were rich and there seemed to be greatest interest and need. In the final phase of the project these new courses were to be taught and evaluated at all participating institutions in the region.

The University of Michigan organized and designed the project, and other universities, colleges, and community colleges were invited to participate. ${ }^{3}$ As the major research institution in the state, The University of Michigan was the logical host, and it is especially rich in resources for the study of women. There is a group of highly regarded scholars, particularly in the social sciences, who do research on women; a vital Center for Continuing Education of Women which had sponsored several Research on Women Conferences and published their results; excellent scholarly resources were available in the libraries, and there was a successful and energetic Women's Studies program willing to sponsor the project.

The proposal submitted to the National Endowment for the Humanities stressed these institutional strengths, and justified the project on several kinds of grounds. ${ }^{4}$ The study of women was placed within the context of recent trends in social history, where the emphasis has shifted from the study of small numbers of elite individuals to the study of larger nonelite groups. The focus on women in the social sciences was shown to be part of a parallel broadening movement in the arts, where the study of high culture has been complemented by the study of popular culture. The need for teaching and research about women was also justified on grounds of social equity. We argued that demands for equity should be based on the knowledge which derives from humanistic study. Finally, the case was made that there would be an increased demand for knowledge about women resulting from the growing numbers of women in the university and in the labor force.

We also articulated several more specific goals for the project. We wanted to build and strengthen the network of Women's Studies scholars and teachers in the region, both within universities and colleges and among them. We wanted to develop courses which would introduce concepts and methods of the disciplines as well as the substantive scholarship on women. Finally, we wanted to integrate the growing scholarship on women into the Women's Studies classroom.

The project was funded to begin in the Fall of 1976, and developed in the stages outlined above. After a four-month planning period, the Research on Women Seminar began in 
January of 1977. Faculty and graduate students from colleges, community colleges, and universities in Southern Michigan came together weekly for the seminar; scholars in the social sciences and the humanities from universities in the United States were invited to present their research. We tried to include speakers who represented a broad range of fields and viewpoints, including both those working within and those outside academic institutions. We invited both distinguished well-known scholars and younger faculty. We also devoted several sessions to the discussion of the teaching experiences of seminar members.

In the second stage of the project (Summer of 1977) we began the difficult task of developing curricular materials. The Seminar commissioned task forces of its members to develop courses in four broadly-conceived interdisdisciplinary subject areas: women and identity, women from a cross-cultural perspective, women and the arts, and women and the American experience. Each task force, composed of six to eight members (graduate students and faculty) was responsible for designing one course. This included assembling and annotating bibliographic materials, developing study questions, and gathering any other materials which might prove useful to teachers. In addition, the task forces outlined background lectures, wrote summaries and critiques of the central debates within their subject area, and developed lists of questions that could be posed in class discussion or made into paper or examination topics. The task forces deliberately gathered more material than could be covered in a one semester course so that teachers would be able to select from the collection the materials best suited to their needs.

In the last stage of the project each course was piloted at one or more of the institutions participating in the project, and they were made available at nominal cost to teachers of Women's Studies throughout the United States. ${ }^{5}$

\section{THE WOMEN'S STUDIES CURRICULUM SERIES}

The Series contains four volumes of curricular materials organized as broadly interdisciplinary Women's Studies courses: Women and Identity (150 pp.), Women's Art and Culture (77 pp.), A Cross-Cultural Study of Women (132 pp.), and New Woman, New World: The American Experience (114 pp.). Each course is organized thematically or topically and is designed for use in a variety of institutional settings. The four volumes in the Series are described below.

\section{Women and Identity}

Women and Identity ${ }^{6}$ is organized around seven major themes: sexuality, fertility, work and family, fear and envy, women's networks, individuality, and women and social change. The course assumes that women's identity has been too narrowly defined, and that seemingly disparate materials must be brought together to expand that definition. Thus, Women and Identity draws upon psychology, sociology, mythology, history, religion, art, literature, and feminism. Each of the seven units in the course contains introductory remarks, lecture outlines, questions for discussion, and bibliographic items for students and teachers. In addition, we include a review of the literature on sex-role learning and a brief analysis of Simone de Beauvoir's work.

The course begins with an examination of sexuality, for women have often been defined solely in sexual terms. After looking at mythic representations of sexual stereotypes, we 
explore the standard psychological theories about the nature of women's sexuality, and then consider how virginity functions as a central idea in western culture. Lesbianism and bisexuality are discussed as alternative definitions of female sexuality. Unit Two examines fertility, with topics ranging from Mother goddesses to modern methods and attitudes toward birth control, child-rearing, and parenting. Students are asked to explore these topics in the context of their own experience of women and experience as women.

Unit Three, Work and Family, looks at two major forces which shape women's identity. The unit is divided into five sections. The first discusses theories about the evolution of the family; the second examines the structure of the family in the contemporary United States, and includes demographic, economic, psychological, and sociological perspectives; the third section discusses women's labor force participation in the United States; the fourth looks at family variants, particularly working-class families, the Black family, single-headed households, and childless families; the last section looks broadly at the psychological and sociological aspects of work. The unit ends with a list of fiction which illumines the theme of work and family.

In Unit Four, Fear and Envy, we turn to an examination of the psychic forces underlying the oppression of women and distorting the image of woman. Menstruation is explored as the locus of men's fear and envy of women's reproductive capacities. We also analyze the phenomena of rape and of witch-hunting, for they reveal similar manifestations of fear and envy. The unit includes a collection of quotations from the works of philosophers, psychologists, political leaders, and writers which reveal the depths of man's fear and envy of woman.

Unit Five, Women's Networks, assumes that women define themselves differently in interaction with other women than with men. We first consider historical, anthropological, and sociological perspectives on women's networks, and compare relationships among women in societies where the political and domestic spheres are integrated with those in societies where they are not. The next section explores the informal, literary, and religious networks that women have created, and the last section describes institutional and organizational networks.

Women's Networks illustrates one organizing principle of the course, and of the Series as a whole. In order to adequately treat the subject of women's experience, we often need to illumine the connections among disparate materials. Thus, within the topic of networks we include female friendships and lesbian relationships; women's participation in salons, midwifery, nursing, and in prostitution; women's role in monastic organizations, in consciousness raising groups, in academic women's caucuses, and in Women's Studies Programs. By showing what these activities have in common the unit explores forces which have brought women together and created bonds among them.

Unit Six, Individuality, reviews the philosophical and anthropological analyses which explain women's secondary status, explores psychological and physiological data, cultural definitions of women's identity, and concludes by discussing feminist critiques of these theories.

In the last unit of the course, Women and Social Change, we try to show students when, how and why women's identity has changed in response to social change. The unit first explores the idea of matriarchy, in theory and in myth; it then examines the Women's Rights Movement and Social Feminism, considers women's participation in social movements throughout history, and analyzes the Women's Movement as a social movement since 1960 . We conclude by looking at the techniques which encourage women to develop 
new awareness of themselves as women: consciousness raising, assertiveness training, self-defense, body awareness techniques, physical fitness, and competition.

Women and Identity has been successfully taught at the introductory level, although some of the materials are difficult. We find that teachers need to focus the course on a single unifying theme (for example, 'views of maternity') and must demonstrate how the materials fit together. Tavris and Offir's The Longest $\mathrm{War}^{7}$ has proven extremely useful as a basic text.

\section{New Woman, New World: The American Experience ${ }^{8}$}

This course works well at the introductory level, for it clarifies basic concepts in Women's Studies and makes them accessible to students. The course is organized into three large units, each containing a short general introduction, specific introductions for each topic area, fully annotated bibliographic materials, and study questions. There are required and recommended readings, plus full descriptions of audio-visual materials. Teachers find particularly useful the specific and detailed annotations; e.g. individual poems are recommended, and shown to be appropriate vehicles to explore particular themes.

Unit One, the Emerging American Woman, considers the process of learning to be female in American society. It summarizes the standard psychological and biological explanations of female identity and then considers the socialization process. The special problems of those who are black, Native American, or immigrant women are analysed. After examining the schooling process as it mirrors and enforces gender roles, this unit ends with a focus on the particularly female dilemma of 'confronting the split self': living in a society whose definition of a healthy female differs radically from its image of a healthy human being.

Unit Two, Woman Self and Others moves away from a focus on woman's individual development to consider her external environment. It begins with a look at the patriarchal family, and then considers possible alternatives to that structure: matriarchies, communes, extended families, and women living alone. After a brief look at the large topic of women and work in America, the unit concludes by examining the effect of health care systems on women's minds and bodies.

Unit Three, The Transcendent Self, considers ways in which women have tried, at times successfully, to break out of the narrow confines of the female role. It considers women who have been agents of social change, looks at artists who have explored new visions for women, and explores some activities (self-awareness techniques, assertiveness training, consciousness raising, and the new women's athletics) that have helped women to expand their horizons.

New Woman, New World also contains a supplementary bibliography, organized by topic, which includes guides to audio-visual materials (including films) and a list of source books on women. Since the list is fully annotated teachers will be able to select items which best suit the background, level, and needs of the students.

The appendix to the course also includes supplementary pedagogical materials. First, there is a guide to oral history interviews. We have found that students profit from interviewing women in their families and communities, and we recommend a set of questions which will guide their exploration. Next, a common and again highly successful assignment has been the 'Notable American Woman' paper. ${ }^{9}$ Students are asked to choose a little known but interesting woman, and to explore her growth and development within the 
context of her times. This assignment teaches basic research skills to beginning students, and requires that they learn how to interpret the data they find.

\section{Women's Art and Culture ${ }^{10}$}

Women's Art and Culture presents five major approaches to the subject of women's participation in the arts. The first unit, which introduces the conceptual framework of the course, examines the conventional roles for woman in the arts, first as subject of (usually male) art and then as creator of her own works. The distinction between decorative ('high') art and functional ('low') art is shown to be crucial to the appreciation of women's ambiguous status in the arts. Homemaking is considered as an expression of women's creative drive. There follows a discussion of how great artists are made by rather than born into American culture, the role of the art establishment as an arbiter of taste, and how the myth of the great artist by its very assumptions excludes most women. The unit then looks at overlooked women artists, and explores who they were, how they were forgotten, and how this lost heritage may affect the work of other women artists.

Unit Two, Women's Oppression and Creativity, examines the roles women have played within and outside the mainstream art establishment. It assumes that all artists have spiritual, intellectual, and material needs, factors which are rarely considered when we evaluate the conditions of women artists. Next, successful women artists within the mainstream are introduced, along with those who have successfully combined a career as an artist with major domestic responsibilities. We then consider women artists who have succeeded in traditional female art forms such as needlework, cooking, interior decorating, diaries and journals (in the West), and in textiles and fibers, pottery, ceramics, and basketry (in non-Western cultures). These forms are shown to be essentially contiguous, and undervalued in the West because they are functional rather than purely decorative art.

Unit Three, Women on Women, looks at how women artists in various media have portrayed themselves, and in the process examines several recurring themes: female adolescence; women's lives in domestic and work environments; female themes and erotic imagery. It shows how women artists have used ideas of female-centered, female-dominated, and all-female societies both to inspire their art and to provide an alternative vision.

Unit Four, Art and Politics, examines the roles of artists in movements for social change and looks at the impact of feminism on women artists. It shows how women artists, like minority artists, may through the 'insights of marginality' convey their critique of the norms of the dominant group.

Unit Five, Great Women and Great Art, introduces major women artists in various media who merit individual study: writers, painters, sculptors, photographers, musicians, dancers and choreographers, women artists in theatre and film, and 'interdisciplinary' artists who have tried to break down distinctions between artistic media.

The authors of Women's Art and Culture list the following goals for the course: ${ }^{11}$

- Becoming acquainted with women artists, their work and their vision

- Getting our history and culture back

- Breaking down the barriers between artists and society, between creators and the public

- Recognizing our personal needs for beauty and for expression

- Gaining confidence in our own creativity and ability to judge and define art 
- Learning how to appreciate, judge and criticize art

- Seeing ourselves through women artists' visions

- Trying to ascertain whether there is a distinctly female vision or female aesthetic

- Questioning the role artists play in culture and society

- Coming to recognize art as a crucial and central part of a fulfilling life

- Recognizing that there can be 'art' wherever there is beauty and imagination

- Learning about the achievements of women in the arts, so that women artists can serve as role models

- Studying the barriers to women in the arts and strategies for overcoming them

- Overcoming narrow categorization of art-forms and coming to understand their cross-fertilizations.

Clearly, this is an ambitious course, and good audiovisual materials are crucial to its success. Slides, tape recordings and records, and films are listed in the bibliography, and many excellent class assignments and group activities are suggested throughout. This course has been successfully taught at a large research university as well as in a community college setting.

\section{A Cross-Cultural Study of Women ${ }^{12}$}

A Cross-Cultural Study of Women is perhaps the broadest in scope of the courses in the Curriculum Series and organizationally the most complex. It contains two kinds of analysis: theoretical overviews and area studies. The theoretical overviews introduce the central questions preliminary to any cross-cultural study of women: (1) the role of biology and of culture in explaining male dominance; (2) how economics enforces gender inequality; and (3) how religion mirrors and reinforces social attitudes, while at the same serving as a potential instrument of liberation.

The first theoretical overview on male dominance begins by summarizing the arguments of contemporary biological determinists, notably Schenfeld, Goldberg, Tiger and Fox. It poses the central questions which must be raised in examining the arguments of the biological determinists, and discusses the ways in which current research into sex differences supports or challenges their assumptions. The analysis turns to the psychological determinists, focussing on Freud's theory of the female personality and the views of his major critics, and then explores the work of Margaret Mead, representative of the theorists who consider culture to be the significant force in shaping gender inequalities. The section ends with a critical appraisal of feminist explanations of sex differences and looks particularly at the work of Nancy Chodorow.

The second theoretical overview on male dominance considers the methodological issues which must be addressed in any cross-cultural study of women, including the method by which one measures status. It stresses the importance of interpreting data within the context of the culture from which it came. The section tries to make sense of the contemporary debate about matriarchies, examining the available evidence as well as the ideological frameworks of writers on both sides of the controversy. There follows a brief analysis of the status of women in horticultural, agricultural, and pastoral societies, introductory material which is designed to help the student accurately interpret the data in the six cultures treated in the second half of the course. This overview concludes by examining recent scholarship 
on gender stratification. The work of Kathleen Gough on the origin of the family, Gayle Rubin's analysis of the sex/gender system, and Sherry Ortner's work on woman and nature are considered as possible approaches to a resolution of the debate over biology versus culture.

The next theoretical overview, Women and Economics, examines theories which consider the role and status of women from an economic perspective. The work of contemporary feminist theorists, as well as that of Marx and Engels, is discussed. The section ends with a focus on women and development, and includes a critical reappraisal of the idea of 'progress' as it reflects the changing status of women.

The next major unit, Women and Religion, attempts to explore an extremely complex area. It demonstrates that religion serves both as a mirror of and means of reinforcing social attitudes, yet at the same time has been a force which women have used to seek liberation. An examination of female-centered religions points out that the mere existence of female deities does not guarantee high female status in a society. Within each of these topics the bibliographical items are annotated, as the student will find much of the reading highly theoretical and controversial.

The second half of $A$ Cross-Cultural Study of Women consists of six area modules on women in South Asia, China, Melanesia, Africa, Latin America, and the Islamic Middle East and North Africa. The modules on South Asia, China, and Melanesia are the fullest, containing lecture outlines as well as annotated bibliographical materials. Those on Africa, Latin America, and the Islamic Middle East and North Africa are presented in the form of annotated bibliographies from which teachers must prepare their own lectures. Each module differs slightly in organization, depending in part upon the materials available and the issues to be treated, yet each considers the status of woman from within the context of the culture in which she lives.

As has been suggested, this course is structurally complex and contains difficult material. We do not recommend that it be taught at the introductory level; students should have some background in the social sciences, preferably in anthropology. It works well when taught by several instructors with combined expertise in the social science disciplines. The annotated bibliographies may be most useful to teachers who wish to broaden their own knowledge of women in other cultures, and to upper-class students working on research projects.

The four volumes of the Curriculum Series range widely over many topics, vary considerably in structure as well as in approach, and have many possible uses. While they were designed as intermediate level Women's Studies courses (to fill the gap between the now popular interdisciplinary 'introduction to Women's Studies' courses and the more specialized research seminars), much of the material is useful at the introductory level. The Series also provides resources for teachers who want to add material on women to courses in the traditional curriculum. A teacher of Chinese History or Literature could adopt materials from the Women in China unit of $A$ Cross-Cultural Study of Women, for example; a Home Economics teacher might find in Women's Art and Culture a surprising perspective on homemaking. The courses also work well in combination. For example, several of the courses contain material on the idea of matriarchy yet each offers a different viewpoint; a teacher wishing to develop a full unit on the subject might combine these sections. The Series as a whole can provide a solid curricular base for a college or university's newly founded Women's Studies program, as well as offer the means to enrich and update the curriculum of a well-established program. 


\section{CONCLUSIONS}

Working intensively in curriculum development in Women's Studies leaves one enthusiastic about the future of the field as well as aware of difficulties. Ideally Women's Studies offers an original approach to teaching both substantive material and methods of inquiry in the social sciences and humanities. As we explore how the disciplines have treated or failed to treat the subject of women, we demonstrate the strengths and limitations of various methods of inquiry. This is an exciting process, and, when it works, teaches students to think critically, a primary aim of education.

Women's Studies teachers do face a danger, however. The teacher who has herself been drawn to the field because of its intellectual challenge to the disciplines may attempt to engage her students at the same advanced point: she finds herself teaching Juliet Mitchell to students who haven't read Freud. The student is quickly overwhelmed, and lost. We must begin at the beginning of our inquiry: the student must struggle with rhe original texts in order to develop the analytical tools and confidence necessary to defend a coherent feminist view of her own.

Finally, it is clear that Women's Studies is an academic field based on a scholarly foundation. At the same time, it cannot divorce itself from contemporary social and political concerns. Indeed, it is interesting to see that three of the four volumes in our Curriculum Series include a unit on women and social change or social protest. It is our belief that Women's Studies need not retreat into scholarship but rather can become a vital source of knowledge and inspiration for feminists within and outside academic institutions working to secure equal rights and status for women.

\section{REFERENCES}

1. The Series began with Female Studies I, edited by Shelia Tobias (Pittsburgh: KNOW, 1970), a collection of seventeen course descriptions and bibliographies. The most recent volume is a collection of student work in Women's Studies classes, Female Studies X: Student Work, edited by Deborah Silverton Rosenfelt (Old Westbury: The Feminist Press, 1975).

2. For a recent example of work in this area, see Lorelei R. Brush, et al., 'The paradox of intention and effect: a Women's Studies course', in Signs, Journal of Women in Culture and Society (The University of Chicago Press, Summer 1978).

3. The following institutions joined the project: Eastern Michigan University, Central Michigan University, Western Michigan University, and Schoolcraft College.

4. The proposal summarized here was developed by Louise A. Tilly, Associate Professor of History and former Director of The University of Michigan Women's Studies Program.

5. Mary I. Edwards, editor, Women's Studies Curriculum Series, The University of Michigan, 1977. For information about ordering the Series, write Women's Studies Program, The University of Michigan, Ann Arbor, Michigan 48109.

6. By Ann Coleman, Susan Haas, Susan G. S. McGee, Ann Munster, Meda Rebecca and Louise A. Tilly.

7. Tavris, Carol and Offir, Carole. 1977. The Longest War: Sex Differences in Perspective. (New York: Harcourt, Brace, Jovanovich.)

8. By Carlene Bagnall, Martha Brown, Doris Corbet, Daryl Hafter, Marilyn Huss, and Nancy Kushigian.

9. This assignment can be easily adapted for students in other countries.

10. By Nancy Faires Conklin and Vivian Patraka.

11. Ibid., pp. 5-6.

12. By Margot Morrow, Martha Brown, Ann Munster, Karen Sinclair, Charlotte Staelin, Norma Ware, and Lance Morrow.

Courses from the Women's Studies Curriculum Series (Mary I. Edwards ed.) are obtainable at $\$ 2.50$ each from: Women's Studies Curriculum Series (Order), Women's Studies Program, 1058 L.S.A. Building, The University of Michigan, Ann Arbor, MI 48109, U.S.A.

Cheques should be payable to: Women's Studies Curriculum Development Project. 